\title{
Oral Hypoglycaemic Agent Metformin Reduces Oxidative Stress and Improves Kidney Histologyin Streptozotocin-induced Diabetic Rats
}

\author{
*1Z.U Umar, ${ }^{2} \mathrm{~A}$. Ishaka, ${ }^{3} \mathrm{~A}$. Abu Bakar and ${ }^{3} \mathrm{M}$. Mohamed \\ ${ }^{1}$ Department of Physiology, College of Health Sciences, Usmanu Danfodiyo University Sokoto, Nigeria \\ 2Department of Medical Biochemistry, College of Health Sciences, Usmanu Danfodiyo University, Sokoto, Nigeria \\ ${ }^{3}$ School of Medical Sciences, Universiti Sains Malaysia, Kubang Kerian, Kelantan, Malaysia \\ [ ${ }^{\star}$ Corresponding Author: E-mail: mahaneem@usm.my; D: +60199387488]
}

\begin{abstract}
Persistent hyperglycaemia results in complications in diabetes mellitus (DM) and metformin is the baseline drug used in diabetic management. The effect of metformin on fasting blood glucose (FBG), homogenized kidney tissue malondialdehyde (MDA), protein carbonyl (PCO), total antioxidant capacity (TAC) and histology in streptozotocin-induced diabetic rats were investigated. Eighteen Sprague Dawley rats were assigned into three groups $(n=6$ rats per group i.e. A; negative control on distilled water, $B$; positive control on distilled water and C; on $100 \mathrm{mg} / \mathrm{kg} / \mathrm{day}$ metformin groups. Diabetes mellitus (DM) was induced using streptozotocin $65 \mathrm{mg} / \mathrm{kg}$ intraperitoneally and treatments were given daily by oral gavage for 3 weeks. Plasma fasting blood glucose (FBG), kidney tissue oxidative stress markers and histology were determined. The results showed that FBG, MDA, and PCO levels were significantly higher in $B$ group compared to $A$ group, and lower in $C$ group compared to $B$. The TAC level was significantly lower in $B$ compared to $A$ and higher in $C$ compared to $B$ group of rats. Histological study showed improvement in kidney histology in all treatments, however, kidney weight did not differ. The results suggest that, metformin reduces oxidative stress in streptozotocin-induced diabetic rats possibly through its antihyperglycaemic effect.
\end{abstract}

Keywords: Diabetes, Metformin, Oxidative stress, Streptozotocin, Kidney.

\section{INTRODUCTION}

Diabetes mellitus (DM) is a pandemic disease associated with hyperglycaemia, polyphagia, polyuria and polydipsia, resulting from defects in insulin secretion, action or both (International Diabetes Federation, 2014; American Diabetes Association, 2017). This disease can affect all the systems in the body leading to increased morbidity and mortality rate worldwide (Gerd et al., 2016). The Oral hypoglycaemic agent metformin has been the primary therapy for hyperglycaemia for many decades with many elucidated mechanisms of action such as inhibition of hepatic gluconeogenesis, antiglucagon action and insulin sensitizing activity (Boyle et al., 2010). Similarly, metformin is known to reduce intestinal glucose absorption and stimulates peripheral glucose utilization (Hur and Lee, 2015). This drug belongs to the class of biguanides which lower blood glucose level without causing hypoglycaemia (Scheen, 1996). Diabetes mellitus promotes glucose auto-oxidation to release reactive oxygen species (ROS) and free radicals leading to increase oxidative stress. The beta cells of the pancreas are themselves sensitive to ROS because they have low antioxidant enzymes. The ROS have been shown to be toxic to the body by selectively damaging proteins of some vital organs such as heart and liver (Gordon et al., 2015).

A study by Obi et al. (2016) showed metformin, significantly improved plasma antioxidant enzymes (superoxide dismutase, catalase and glutathione reductase) and reduces malondialdehyde (MDA) levels in alloxaninduced diabetic animal model at a dose of between $25-100 \mathrm{mg} / \mathrm{Kg} /$ day. A similar study revealed metformin at a dose of 50 to 200 $\mathrm{mg} / \mathrm{kg} / \mathrm{day}$ administered for 2 weeks significantly normalized blood glucose, improved insulin and reduced MDA levels in fructose fed rats model of type 2 DM (Anurag and Anuradha, 2002). Moreover, in human it was observed that, metformin is very effective in reducing FBG level and oxidative stress compared with the lifestyle modification 
(Esteghamati et al., 2013). This could be the reason why recently metformin, including some other oral hypoglycaemic agents, are suggested as adjuvant in the management of many diseases such as obesity and cancer (Violet et al., 2012). In this regards, there is need to investigate the effect of metformin on kidney oxidative stress status and histology in diabetic animal model. Therefore, this study was undertaken to establish the effect of metformin on homogenised kidney tissue MDA, PCO, TAC and histology in streptozotocininduced diabetic rats.

\section{MATERIALS AND METHODS \\ Animals}

Eighteen 8-10 weeks old Sprague Dawley rats weighing between 190-220 g were purchased from the animal house of the Universiti Sains Malaysia, Health Campus Kelantan. Animals were kept in polypropylene cages with wood shavings bedding in a well-ventilated room and were allowed free access to chow feed and water ad libitum for one week to acclimatise. Animals Ethical Approval was obtained from Universiti Sains Malaysia ethical committee (USM/Animal Ethics Approval/2013/90/503).

\section{Chemicals and Kits}

All other reagents used for the study were of analytical grade. Streptozotocin was purchased from Sigma Aldrich (Chemical Co. UK), digital glucometer was purchased from Muenster (Accu-Chek, Roche, Germany), Elizer commercial kits was also purchased for the assay of homogenized kidney oxidative stress markers TAC (TA02; Biomedical Res), MDA (NWK-MDA01; NWLSSTM), PCO(Assay Kit; Cayman).

\section{Diabetes Mellitus (DM) Induction}

Induction of DM was achieved using intraperitoneal injection of STZ at a single dose of $65 \mathrm{mg} / \mathrm{kg}$ body weight in phosphate buffer solution to 12 rats after fasting for 16 hours (Umar et al., 2015). Six rats received an equal volume of phosphate buffer only. FBG was measured using a glucometer based on glucose oxidase method 48 hours post STZ administration (Trinder, 1969). Animals with
FBG level of $\geq 11.1 \mathrm{mmol} / /$ were considered diabetic and included in the study.

\section{Experimental Design}

Twelve rats were randomly assigned into two groups and the remaining as negative control ( $n=6$ rats per group) i.e.

Group A: as negative control (Non diabetic; on $1.0 \mathrm{~mL} /$ day of distilled water)

Group B: as positive control (Diabetic; on 1.0 $\mathrm{mL} /$ day of distilled water)

Group C: as experimental (Diabetic on100 $\mathrm{mg} / \mathrm{kg} /$ day of metformin dissolved in $1 \mathrm{~mL}$ distilled water).

Treatment was administered daily for 3 weeks, after which all animals were fasted overnight, FBG was taken and the animals were then sacrificed. Kidneys of the sacrificed rats were harvested for histology and homogenization to determine TAC, MDA and PCO using commercial kits as described. The tissues for histology were processed using standard histopathological procedure for Haematoxylin and Eosin ( $\mathrm{H}$ and $\mathrm{E})$.

\section{Statistical analysis}

Data were analysed using statistical software InStat 3.1 (Charlesworth Group Ltd, Huddersfield, UK). Result are expressed as mean and standard deviation (SD) ( $n=6 /$ group) and analysed for statistical significance $(p<0.05)$ using one-way analysis of variance (ANOVA) followed by Tukey-Kramer post-hoc test.

\section{RESULTS}

\section{Fasting blood glucose levels}

The mean FBG level of A group was significantly different from the other groups throughout the study period after induction of DM. On the contrary, FBG level in B group was significantly higher $(p<0.05)$ compared with $A$ group. Similarly in $C$ group treated with 100 $\mathrm{mg} / \mathrm{kg} /$ day, FBG was significantly lower $(p<$ 0.05 ) compared with $B$ group after treatment for three weeks (Table 1). 
Table 1: Fasting Blood Glucose Level for Experimental Groups

\begin{tabular}{lll}
\hline Groups & \multicolumn{1}{c}{$\begin{array}{c}\text { Initial FBG } \\
(\mathrm{mmol} / \mathrm{L})\end{array}$} & \multicolumn{1}{c}{$\begin{array}{c}\text { Final FBG } \\
(\mathrm{mmol} / \mathrm{L})\end{array}$} \\
\hline A & $5.11(1.72)$ & $5.02(1.23)$ \\
B & $25.19(73.33)^{\mathrm{a}}$ & $31.03(49.79)^{\mathrm{a}}$ \\
$\mathrm{C}$ & $27.14(45.14)^{\mathrm{a}}$ & $9.19(42.49)^{\mathrm{a}, \mathrm{b}}$
\end{tabular}

Values are mean (SD), $n=6$ rats per group. $A$, nondiabetic; $\mathrm{B}$, diabetic treated with $\mathrm{DW}$ and $\mathrm{C}$, diabetic treated with metformin. Initial FBG, fasting blood glucose before the commencement of treatment; final FBG, fasting blood glucose after the treatment. aSignificant differencecompared with $A$ group at $p<0.05$; bSignificant difference compared with $B$ group at $p<0.05$ down the column.

\section{Kidney weight}

Absolute and relative weights of kidneys harvested from experimental groups are as shown in Table 2.

Table 2: Absolute and Relative Kidney Weight in experimental groups

\begin{tabular}{lcc}
\hline Groups & $\begin{array}{c}\text { Absolute weight } \\
(\mathrm{g})\end{array}$ & $\begin{array}{c}\text { Relative weight } \\
(\%)\end{array}$ \\
\hline A & $0.052(0.012)$ & $0.022(0.004)$ \\
B & $0.047(0.008)$ & $0.022(0.004)$ \\
C & $0.047(0.008)$ & $0.022(0.004)$ \\
\hline
\end{tabular}

Data are presented as mean (SD), $n=6$ rat per group. $A$, non-diabetic; $B$, diabetic treated with $\mathrm{DW}$ and $\mathrm{C}$, diabetic treated with metformin. No significant difference $(p>0.05)$ observed in all the groups.

\section{Oxidative Stress Markers in Kidney Homogenate}

MDA and PCO were significantly higher while TAC was lower in B group compared with $A$ group. However, MDA and PCO in $C$ group were significantly lower while TAC was higher compared with B group (Table 3).

\section{Kidney histological study}

Kidney glomerular histology was smaller with evident tubular dilatation in B group compared with $\mathrm{A}$ group. However, in $\mathrm{C}$ group treated with $100 \mathrm{mg} / \mathrm{kg} /$ day, glomerular histology was better than B group but smaller than A group (Plate 1).

\section{DISCUSSION}

The lower FBG level in metformin treated diabetic group (group $\mathrm{C}$ ) is in line with previous report on metformin action in comparison with other oral antihyperglycemic drugs glibenclamide and repaglinide, although plasma insulin level was not measured (Obi et al., 2016). This antihyperglycemic action is as a result of metformin ability to reduce blood glucose to a normal level without causing hypoglycaemia, its ability to inhibit hepatic gluconeogenesis, decrease intestinal glucose absorption and increase peripheral glucose utilization (Boyle et al., 2010).

Reactive oxygen species are said to be among the important factors that alter beta cells metabolism and function (Bindokas et al., 2003). Streptozotocin and hyperglycaemia increase free radicals' formation which may overwhelm antioxidant enzyme (Del Rio et al., 2005). This may lead to an imbalance between the levels of oxidant and antioxidant enzyme activity as seen in the present study. Homogenized kidney tissue MDA and PCO were significantly higher while, TAC was significantly lower in $B$ group compared with $A$ group found in the present study may suggest the presence of higher free radicals release with increased oxidative stress in $B$ group. On the other hand, the plasma levels of MDA and PCO were significantly lower while TAC was significantly higher in $C$ group compared with $B$ group showing the indirect antioxidant effect of metformin possibly by its antihyperglycaemic effect. The decreased MDA level is in line with previous study using metformin at the doses of 25-100 (Obi et al., 2016), and 50-200 $\mathrm{mg} / \mathrm{kg} / \mathrm{day}$ (Anurag and Anuradha, 2002). This is further supported by previous study that any substance with radical scavenging potential may have indirect effect on blood glucose level and spare tissue from damages (Kumitoshi et al., 2011). 
Table 3: Plasma oxidative stress markers for all the groups

\begin{tabular}{lccc}
\hline Groups & $\begin{array}{c}\text { MDA } \\
(\mathrm{nmol} / \mathrm{mg} \text { protein })\end{array}$ & $\begin{array}{c}\text { PCO } \\
(\mathrm{nmol} / \mathrm{mg} \text { protein })\end{array}$ & $\begin{array}{c}\text { TAC } \\
(\mathrm{nmol} / \mathrm{mg} \text { protein })\end{array}$ \\
\hline $\mathrm{A}$ & $0.903(0.157)$ & $1.168(0.093)$ & $0.404(0.048)$ \\
$\mathrm{B}$ & $3.223(0.457)^{\mathrm{a}}$ & $3.604(0.303)^{\mathrm{a}}$ & $0.143(0.027)^{\mathrm{a}}$ \\
C & $1.205(0.288)^{\mathrm{b}}$ & $1.701(0.075)^{\mathrm{a}, \mathrm{b}}$ & $0.279(0.036)^{\mathrm{a}, \mathrm{b}}$ \\
\hline
\end{tabular}

Data are presented as mean (SD), $n=6$ rat per group. $A$, non-diabetic; $B$, diabetic treated with $D W$ and $C$, diabetic treated with metformin. MDA, malondialdehyde; PCO, protein carbonyl; TAC, total antioxidant capacity. ${ }^{\text {SSignificant difference }}$ compared with $A$ group at $p<0.05$; bSignificantdifference compared with $B$ group at $p<0.05$.
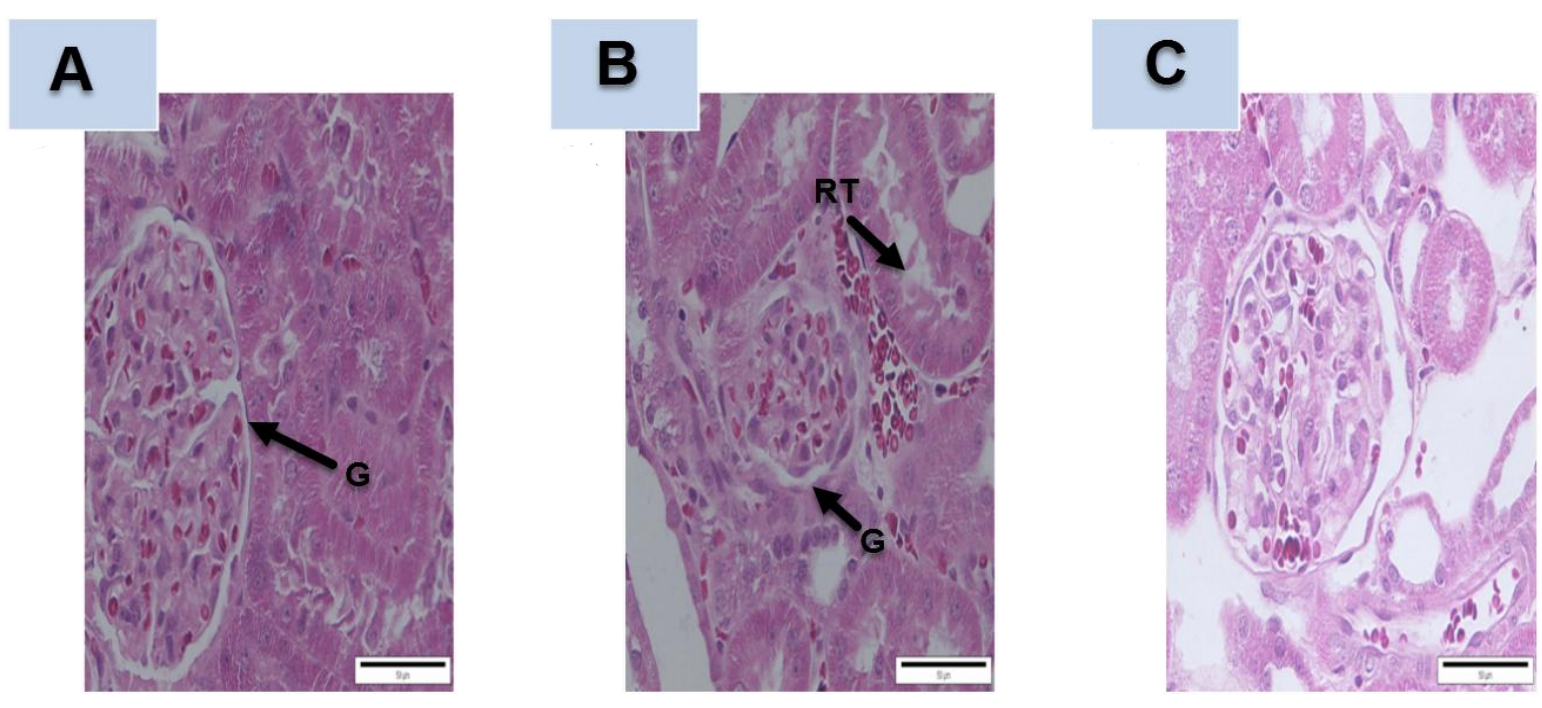

Plate 1: kidney histology after $\mathrm{H}$ and $\mathrm{E}$ staining in all experimental groups.

$A=$ non-diabetic rats; $B=$ diabetic rats treated with $D W ; C=$ diabetic rats treated with metformin. $G=$ glomerulus; $\mathrm{RT}=$ renal tubules.

The poor kidney histology with reduce glomerular size in $B$ group compared with $A$ and $C$ groups could be attributed to higher FBG and oxidative stress markers as seen in this study. Zhang et al. (2016) observed that lipid peroxidation caused by oxidative stress exerts a toxic effect on glomerulus. This is because liver and kidney are the primary targets of toxic metabolic changes such as oxidative stress (Marchesini et al., 2005). It is noteworthy that, the observed ameliorating effect of metformin on fasting blood glucose and oxidative stress may be responsible for the improved kidney histology in the $\mathrm{C}$ group.

\section{CONCLUSION}

The findings in this study suggests that the oral hypoglycaemic agent metformin at a dose of $100 \mathrm{mg} / \mathrm{kg} /$ day for 3 weeks supressed oxidative stress as well as improved kidney histology in STZ-induced diabetic rats possibly through its antihyperglycaemic effect. Further studies are suggested to evaluate the possible beneficial effects of metformin in protecting end organ damage in DM.

\section{ACKNOWLEDGMENTS}

The authors would like to thank Universiti Sains Malaysia for the financial support. USM Research University Grant (1001/PPSP/813072) and Malaysian International Scholarship, MOHE, Malaysia.

\section{REFERENCES}

American Diabetes Association (ADA) (2017). Standards of medical care in Diabetes. Diabetes Care, 37(1): 14- 64.

Anurag. P., Anuradha, C.V. (2002). Metformin improves lipid metabolism and attenuates lipidperoxidation in higher fructose-fed rats. Journal of Diabetes, Obesity \& Metabolism, 4: 36-42. 
Bindokas, V.P, Kuznetsov, A., Sreenan, S., Polonsky, K.S., Roe, M.W., Philipson, L.H. (2003). Visualising superoxide production in normal and diabetic rats islets of Langerhans. Journal of Biological Chemistry, 78: 9796-9801.

Boyle, J.G., Mckey, G.A., Fisher. M. (2010). Drugs for diabetes: part 1 metformin. British Journal of Cardiology, 17:231134.

Del Rio, D., Stewart, A.J., Pellegrini, N. (2005). A review of recent studies on Malondialdehyde as toxicmolecule and biological marker of oxidative stress. Journal of Nutrition Metabolism and Cardiovascular Diseases, 4:316-328.

Esteghamati, A., Eskandari, D., Mirmiranpour, H., Noshad, S., Mousavizadeh, M., Hedayati,M.,Nakhjavani, M. (2013). Effects of metformin on markers of oxidative stress andantioxidantreserve in patients with newly diagnosed type 2 diabetes: a randomizedclinical trial. Journal of Clinical Nutrition, 32:179185.

Gerd, L., Jessica, B., Anke, V., and Rolf, G.(2016). Short and longterm glycemic control ofstreptozotocin induced diabetic rats using different insulin preparations. Plos One, 11: e0156346.

Gordon, E.E., Reinking, E.B., Hu, S., Yao, J., Kua, K.I., Areej, K., Wang, C., Norris, A.W.(2015). Maternal hyperglycemia directly and rapidly induces cardiac septal overgrowthin fetal rats. Journal of Diabetes Research, 1: 11.

Hur, K.Y. and Lee, M.S. (2015) New mechanisms of metformin action: focusing on mitochondria andthe gut. Journal of Diabetes Investigation, 6 : 600-609.

International Diabetes Federation (IDF). (2014). $6^{\text {th }}$ Edition Atlas, revision. 07- 15. Available:

http://www.idf.org/diabetesatlas (Accessed 25 Jun, 2017).
Kumitoshi, U., Katsuya, D., Boldbaata, D., Hitoshi, I., Tetsuya, S., Yasuo, M., Toshihiko, Y.,Yasunhiko, M., Makoto, T. (2011). Lack of TRPM2 impaired insulin secretion and glucosemetabolism in mice. Journal of Diabetes, 60: 119-126.

Marchesini, G., Marzocchi, R., Agostini, F., and Bugianesi, E. (2005). Nonalcoholic fatty liver disease and the metabolic syndrome. Current opinion in lipidology, 16(4), 421-427.

Obi, B.C., Okoye, T.C., Okpashi, E.V., Igwe, C.N., Alumanah, E.O.(2016). Comparative study of the antioxidant effects of metformin, glibenclamide, and Repaglinide in alloxan induced diabetic rats. Journal of Diabetes Research, 1 : 5-10.

Scheen, A.J. (1996). Clinical pharmacokinetics of metformin. Journal of Clinical Pharmacy, 30:359-371.

Trinder, P. (1969). Determination of blood glucose using an oxidase-peroxidase system with a noncarcinogenichromogen. Journal of Clinical Pathology, 2: 158-161.

Umar, Z.U., Ainul, B.A., Mohamed, M. (2015). An updated review on experimental methods of diabetic research: Advantages and Limitations - an updates Review article. Annual Research and Review in Biology, 7:100-108.

Violet, B., Guigas, B., Garcia, N.S., Leclerc, J., Foretz, M., Andreelli, F. (2012). Cellular and molecularmechanisms of metformin: an overview. Journal of Clinical Science, 6:253-270.

Zhang, R., Yu, Y., Deng, J., Zhang, C., Zhang, J., Cheng, Y. \& Yang, H. (2016). Sesamin Ameliorates High-Fat DietInduced Dyslipidemia and Kidney Injury by Reducing Oxidative Stress. Nutrients, (5):276. 